\title{
An improved normalized seawater strontium isotope curve based on an updated compilation of Precambrian seawater ${ }^{87} \mathrm{Sr} /{ }^{86} \mathrm{Sr}$
}

\author{
XI CHEN, YING ZHOU AND GRAHAM A SHIELDS
}

University College London

Presenting Author: helen.xi.chen.19@ucl.ac.uk

The secular trend of seawater ${ }^{87} \mathrm{Sr} /{ }^{86} \mathrm{Sr}$ retained in marine authigenic minerals reflects changes in the relative contributions to ocean composition of continental versus mantle chemical reservoirs, and informs global tectonic events, weathering rates and biogeochemical cycling through Earth history. However, the existing Precambrian strontium isotope curve has inadequate temporal resolution, necessitating fresh compilation and documentation of pertinent strontium isotope data. In this study, we have compiled an additional 2038 strontium isotope values for Precambrian marine carbonate rocks of the past 18 years. We assigned both newly and previously compiled data to one of three groups: high-quality data; medium-quality data; and lowquality data, using four criteria (diagenetic alteration, depositional environment, dissolution method and age constraint). We proposed an improved Precambrian seawater ${ }^{87} \mathrm{Sr} /{ }^{86} \mathrm{Sr}$ curve based mainly on the high-quality data. This updated seawater ${ }^{87} \mathrm{Sr} /{ }^{86} \mathrm{Sr}$ curve shows an overall increasing trend from $\sim 0.7005$ at c. $3.5 \mathrm{Ga}$ to $\sim 0.7089$ towards the end of the Ediacaran Period with stronger oscillations and better correspondence with supercontinent cycles than previously shown.

To fully realise the potential of the updated seawater ${ }^{87} \mathrm{Sr} /{ }^{86} \mathrm{Sr}$ curve tracing globally integrated chemical weathering rates, we normalized the seawater strontium isotope curve against the isotopic evolution of three major $\mathrm{Sr}$ sources (carbonate dissolution, silicate weathering and submarine hydrothermal exchange) to the ocean. Based on methodologies in Shields, $(2007)^{[1]}$, we tested three crustal evolution models and different carbonate to silicate weathering ratios proposed during recent years to achieve the best-fit model and parameters. Here we propose an improved, normalized seawater strontium curve showing earlier mafic crust differentiation (before $3.5 \mathrm{Ga}$ ) and baselines fluctuating between $\sim 40 \%$ and $\sim 50 \%$ since c. $3.0 \mathrm{Ga}$ without significant shifts. Three continental weathering peaks (80\%-90\% river runoff) at around $2.4 \mathrm{Ga}, 1.7 \mathrm{Ga}$, and $500 \mathrm{Ma}$ coincide with assembly of the Kenorland, Nuna and Gondwana mega/supercontinents, respectively. Potential links between these extreme continental erosion events and key steps in biological evolution as well as their implications for global carbon cycling await further evaluation.

[1] Shields, G. A. (2007). A normalised seawater strontium isotope curve: possible implications for NeoproterozoicCambrian weathering rates and the further oxygenation of the Earth. EEarth, 2(2), 35-42. 